\title{
Conflicto y violencia: contenidos formativos en los grados en Periodismo de las universidades españolas
}

\author{
María Ángeles Galván ArIAs \\ Universidad CEU San Pablo \\ marigelgalvan@gmail.com
}

\section{Resumen}

En los estudios de Grado en Periodismo españoles resulta llamativamente pobre la presencia de asignaturas que se orienten de modo especializado hacia la formación y capacitación del alumnado en las materias que se vinculan con la información sobre los hechos y acontecimientos relacionados con los conflictos y la violencia (conflicto armado, terrorismo, violencia de género, acoso escolar, bandas juveniles, violencia en el deporte, conflictividad laboral) pese a la trascendencia social y profesional de la temática. Fenómeno que se agrava por el significativo carácter optativo de esa oferta educativa.

Palabras clave: Conflicto; violencia; periodismo; EEES; España

\section{Conflict and Violence: Training Content in the Degrees in Journalism from Spanish Universities}

\begin{abstract}
In the studies programs of a degree in Journalism from Spain it is strikingly poor the presence of subjects that oriented specialized mode toward the formation and training of the students in the matters linked with the information on the facts and events relating to conflict and violence (armed conflict, terrorism, gender violence, bullying, gangs, violence in sports, industrial disputes) despite the social significance and professional thematic area. The phenomenon is compounded by the significant optional nature of the educational offer.
\end{abstract}

Key words: Conflict; violence; journalism; European Higher Education Area; Spain

\section{Referencia normalizada:}

Galván Arias, M. A. (2013) Conflicto y violencia: contenidos formativos en los grados de Periodismo de las universidades españolas. Historia y Comunicación Social. Vol. 18 No Especial Octubre. Págs. $711-721$

Sumario: 1. Introducción. Conflicto, violencia y periodismo. 2. Educar a periodistas competentes y responsables. 3. Metodología. 4. Los contenidos formativos: periodismo, conflicto y violencia. 5 . Conclusiones. 6. Referencias bibliográficas. 7. Notas 


\section{Introducción. Conflicto, violencia y periodismo}

"Nadie consagrado a pensar sobre la Historia y la Política puede permanecer ignorante del enorme papel que la violencia ha desempeñado siempre en los asuntos humanos, y a primera vista resulta más que sorprendente que la violencia haya sido singularizada tan escasas veces para su especial consideración", sentenció la pensadora Hannah Arendt (2006: 16). El conflicto ha sido tradicionalmente un incuestionable criterio periodístico de lo noticioso.

La pugna - antagonismo, lucha, pelea, disputa, competencia, discrepancia, desacuerdo - forma parte de la existencia humana que, en definitiva, es la materia prima del quehacer informativo: contar lo que el ser humano obra y narrar aquello que le acontece. La tarea de un reportero responde a la esencia de recorrer el lugar donde suceden los hechos, observar cuanto ocurre y relatárselo con honestidad a la ciudadanía. Pero para tratar de impedírselo, los bandos enfrentados le plantean al periodista innumerables trabas y le colocan toda clase de obstáculos. Quienes combaten, los violentos, pretenden ante todo cegar su visión del acontecimiento y pretenden suprimir cuantas palabras o imágenes encierran sus mensajes y les resultan incómodas. Una estrategia de silenciamiento que no es exclusivo, por supuesto, de los campos de batalla, porque el frente informativo de la brutalidad, con frecuencia, en cualquier lugar del planeta, se localiza unas esquinas más allá de cualquier sala de redacción: el terrorismo, la violencia de género, el racismo, los abusos sexuales...

Como reflexiona Penalva (2002: 395), la conflictividad que deriva en actos violentos, sean físicos o culturales, resulta connatural al ser humano:

Los medios de comunicación desempeñan un papel muy importante en la conformación de estas representaciones ideológicas de la violencia, pero no son las únicas instituciones inmersas en este proceso. La violencia de los medios de comunicación (la que aparece en algunas formas de representarla) es una forma más de violencia cultural que es «coherente» con otras formas e instituciones más eficaces de legitimar la violencia directa y la estructural (educación, ciencia, ideología, ejército, empresa, familia, iglesia) con las cuales comparte el papel de agente de socialización, proceso a partir del cual los individuos aprenden a vivir en su sociedad y su cultura e interiorizan valores y normas de comportamiento.

El relato de la violencia demanda un periodismo comprometido no sólo con la veracidad del relato de los acontecimientos y con la deontología profesional, sino con la búsqueda del entramado de significados que a menudo dificultan acceder a la esencia que da sentido al hecho mismo. Esto es, el estudio de las maneras y mecanismos de legitimación de la violencia que aparecen en los medios de comunicación. Máxime, cuando se mixtura el mensaje con elementos de necesaria denuncia y con pinceladas de mero espectáculo sensiblero, ese macabro entretenimiento en el que se transforma con frecuencia, sobre todo en televisión, para incrementar audiencias (Penalva, 2002: 398; Calleja, 2013).

El rastro de la barbarie inunda portadas de diarios y copa los noticiarios audiovisuales. Y se inmortaliza gracias a la imaginería. Homo homini lupus. "Me opongo a la 
violencia porque cuando parece que consigue el bien, el bien es solamente temporal; el mal que provoca es permanente", colegía Gandhi. Una maldad plasmada en la instantánea desgarradora de Tanara Akbari, una chiquilla aterrorizada, rodeada de sanguinolentos despojos humanos tras un atentado suicida en Kabul, fotografía que resultó galardonada con un Pulitzer en 2012. Y en la siguiente edición del prestigioso premio, el fotoperiodista español Manu Brabo lo obtuvo en reconocimiento por la serie de retratos sobre la crudeza y las funestas secuelas de la guerra civil en Siria. Nos encontramos, de bruces, a diario, "ante el dolor de los demás" (Sontag, 2003).

Entonces, ¿es indispensable mostrar el horror humano? Para el maestro Henri Cartier-Bresson el público poseía el derecho a contemplarlo todo, en el marco de esa interpretación sucesiva de la realidad social que supone el periodismo, que, como explicaba Gomis (2008), posibilita que la gente pueda entenderla, adaptarse a ella y modificarla. También en esa trágica parcela domeñada por el conflicto que, ultrapasada la agresividad, deriva en violencia. El ciudadano, para tomar con libertad sus propias decisiones ha de estar informado: el derecho a saber.

En octubre de 2013, la ONG Action on Armed Violence difundió la lista de los, a su juicio, 100 reporteros más influyentes en la cobertura periodística de la violencia armada. Junto a insignes veteranos extranjeros - Christiane Amanpour, John Lee Anderson, Robert Fisk, Dan Rather, John Pilger - figuran esforzados informadores españoles como Javier Espinosa o Marc Marginedas. La organización recordaba que los periodistas son el puente entre los dos mundos, el pacífico y el violento. Y que sin su valentía y determinación para acercar la realidad de la violencia seríamos incapaces de entender ni resolver los problemas que la causan y propagan.

\section{Educar a periodistas competentes y responsables}

Justamente de la trascendencia de informar y formar sobre los acontecimientos vinculados al conflicto y la violencia dan fe iniciativas como el Institute for War and Peace Reporting y el Dart Center for Journalism and Trauma, un proyecto de la Columbia Journalism School. Ambas instituciones destinan ingentes energías y significativos recursos al apartado instructivo, tanto en el ámbito de la divulgación escolar y en la docencia superior, como en el caso de la formación de los profesionales que ya ejercen y que afrontan en su trabajo situaciones de conflicto y violencia (corresponsalías, periodismo social, información de sucesos y tribunales...). Porque la defensa de los derechos humanos se cimenta igualmente en el acurado tratamiento informativo de las situaciones en que aparece la ira incontenida. Y porque el conflicto y el drama alimentan la industria noticiosa, demasiados actos violentos, síntomas de problemas y situaciones estructurales de nuestra sociedad, se tratan coyunturalmente como meros "sucesos". Una cobertura periodística superficial y frívola que ha generado intenso debate y preocupación tanto en la tribuna profesional como en el mundo académico (Barrios, 2002; CICR, 2003). En este marco resulta determinante 
la educación de los futuros periodistas, crucial para familiarizar al alumnado con estas realidades sociales y comunicativas, máxime en el actual período de consolidación del Espacio Europeo de Enseñanza Superior (EEES) y tras el impulso explícito institucional desde 1993, cuando la Asamblea Parlamentaria del Consejo de Europa aprobó el Código Deontológico Europeo de la Profesión Periodística destacando que, dada la complejidad del proceso informativo, que se basa cada vez más en la utilización de nuevas tecnologías, la rapidez y la síntesis, debe exigirse a los periodistas una formación profesional adecuada (art. 31).

Un referente de entidad para analizar y valorar la presencia de contenidos educativos que se relacionan con el tratamiento informativo de la violencia en la formación de los futuros periodistas es el Plan modelo de estudios de periodismo de la UNESCO (2007), fruto de una reunión consultiva de expertos en París, convocada en diciembre de 2005, en respuesta a las múltiples solicitudes de Estados de todo el mundo preguntando en relación a qué cursos tendrían que integrar un plan de estudios en Periodismo. La propuesta ha sido referente en el EEES. El resultado de la consulta se presentó de modo oficial en el Congreso Mundial sobre Enseñanza del Periodismo celebrado en Singapur (junio de 2007).

Entre las líneas maestras del Plan modelo, se indica que el curso denominado Ética periodística, "prestará especial atención a las cuestiones de sensibilidad y seguridad ligadas a la cobertura periodística de conflictos" (terrorismo, guerras, matanzas, violencia), cuando alude a las cuestiones éticas y problemas recurrentes relacionados con el deber ciudadano. Las premisas de la cobertura informativa sobre la violencia las recoge la International Federation of Journalists (IFJ) (2002) con el fin de que los profesionales de la información respeten de modo escrupuloso los derechos que asisten a las víctimas más indefensas (UNICEF, 2005). Esta preocupación formativa se extiende de igual modo al curso Medios de comunicación y sociedad, un análisis crítico de la función que desempeñan los medios en la construcción de la democracia y las consecuencias de los factores políticos, económicos, culturales y tecnológicos en la actividad de la empresa informativa. Por consiguiente, ha de contemplarse la perspectiva de los medios y el conflicto, incluidos el activismo ciudadano y la violencia y las iniciativas de paz.

Otro hito señalado es la Declaración de Tartu de la European Journalism Training Association (EJTA), elaborada en 2006 y actualizada en 2013, documento que agrupa las competencias periodísticas en diez categorías formativas. La primera es la que alude a la competencia para saber reflexionar sobre el crucial papel que el periodismo desempeña en todo Estado, en que se alude al mantenimiento de un compromiso del periodista con su sociedad, comunidad y público, así como el conocimiento de la evolución de la comunidad. Esta exigencia educativa incluye una familiarización sólida con el tratamiento periodístico de hechos y acontecimientos presididos por la conflictividad y la violencia.

En España, en íntima conexión con esta recomendación, el Libro blanco de la Comunicación de la Agencia Nacional de Evaluación de la Calidad y Acreditación 
(ANECA) recoge para la materia denominada Libertad de expresión, responsabilidad periodística y opinión pública, incluida entre los contenidos comunes obligatorios para el Grado en Periodismo, el "análisis comparado entre los relatos, la retórica y los objetivos que se orientan hacia el conflicto y la desigualdad, y aquellos otros que contribuyen a resolver las confrontaciones y procuran transmitir unos valores de equidad, solidaridad y concordia" (ANECA, 2005: 314). Entre las competencias, habilidades y destrezas a adquirir en este capítulo figura la conciencia igualitaria sobre las personas y los pueblos, y el respeto por los derechos humanos internacionales, así como conocimientos de las grandes corrientes culturales o civilizadoras en relación con los valores fundamentales individuales y colectivos. De igual forma, se contempla la capacidad y habilidad para el análisis del discurso informativo y de sus estrategias para la confrontación o la resolución de problemas. Y, finalmente, se exige la destreza en el análisis de casos y propuestas para discursos periodísticos que fomenten la conciencia igualitaria entre las personas y los pueblos.

\section{Metodología}

Esta investigación tiene como principal objetivo trazar un preciso mapa que muestre el número, naturaleza y contenidos educativos que vinculan, de manera específica y con profundidad, la comunicación, el conflicto y la violencia dentro del marco de los estudios superiores de Grado en Periodismo en España, en conformidad con las directrices educativas que trazan la UNESCO y la ANECA.

Para obtener datos precisos y exhaustivos se elaboró un listado de las universidades oficiales existentes en el curso académico 2012-2013, públicas ( $\mathrm{n}=51)$, privadas $(n=19)$ y de la Iglesia Católica $(n=7)$, ya fueran de naturaleza presencial o de educación a distancia. Sobre el total de instituciones de educación superior españoles $(\mathrm{n}=77)$, se procedió, a continuación, a seleccionar aquellos centros que ofrecen estudios de Grado en Periodismo o Comunicación $(\mathrm{n}=40)$, verificados y aprobados por la ANECA en su programa Verifica, que evalúa las propuestas de los planes de estudio de título diseñados en consonancia con el EEES.

Tras recopilar los planes de estudio objeto de análisis en la versión oficial extraída del Boletín Oficial del Estado (BOE), se procedió a un minucioso estudio de contenido comparado que dibujó una rigurosa cartografía de los contenidos teóricos con que se orienta a preparar ética, técnica y emocionalmente en ese campo a los comunicadores españoles en la educación superior. En el ámbito profesional la formación para la cobertura de conflictos armados de riesgo demanda un entrenamiento de seguridad, como los que facilitan Fuerzas Armadas como en el británico Special Air Service (SAS) o empresas como Tactical Training Institute, amén de un apoyo específico de la empresa periodística (póliza de vida, equipo de protección, ayuda psicológica). En España, Reporteros sin Fronteras (RSF) o el Comité Internacional de la Cruz Roja (CICR) suministran ayuda para informadores en misiones que entrañan peligro. 
Con posterioridad, se confrontó la información recopilada con la que figura en las pertinentes fichas oficiales de las asignaturas objeto de la muestra de análisis al objeto de recabar y confirmar los detalles de las competencias que se prescriben y del temario que se imparte en cada caso. Para el examen de cada unidad de análisis se contemplaron las siguientes variables:

Asignaturas específicas especializadas: centro, denominación, carácter, carga crediticia, curso y ciclo.

Cobertura temática especializada: derechos humanos, periodismo de paz, terrorismo, guerra y conflictos armados, conflictos étnicos y raciales, violencia de género y doméstica, violencia en la calle (juvenil, escolar, deportiva...), conflictos sociales, laborales y medioambientales.

\section{Los contenidos formativos: periodismo, conflicto y violencia}

\subsection{Las asignaturas específicas}

Un primer resultado, de enorme relevancia, es la escasa atención que en general se dedica a la formación profesional periodística en los contextos en los que campea la violencia fruto de un conflicto $^{1}$, cualquiera que sea su etiología (Tabla 1). Apenas el $12,5 \%$ de los planes de estudio oficiales de Grado en Periodismo (o en Comunicación) poseen asignaturas específicas de esa naturaleza. El panorama se ensombrece más aún si atendemos al carácter oficial de la materia, dado que la optatividad adquiere notable presencia $(50,0 \%)$, circunstancia que implica que, a la postre, solo en el 7,5\% de los Grados universitarios en que se forman los futuros periodistas españoles se obligue al alumno a familiarizarse con estos temas, contenidos y tratamiento técnico. $\mathrm{Al}$ menos, de un modo especializado y con suficiente hondura. Todas estas materias se circunscriben a la rama del periodismo especializado, naturaleza que explica su inserción en el último curso de los estudios, cuyo segundo ciclo se consagra, precisamente, a la especialización del alumno, conforme a las directrices que se establecen en el EEES.

Tabla 1. Grado en Periodismo. Asignaturas específicas vinculadas al conflicto y la violencia.

\begin{tabular}{|l|l|c|c|c|}
\hline Universidad & Denominación & Carácter & $\begin{array}{c}\text { Créditos } \\
\text { ECTS }\end{array}$ & Curso \\
\hline Valladolid & Información y derechos humanos & Obligatorio & 6 & $4^{\circ}$ \\
\hline Pompeu Fabra & $\begin{array}{l}\text { Periodismo especializado en } \\
\text { información criminológica }\end{array}$ & Optativo & 4 & $3^{\circ}-4^{\circ}$ \\
\hline
\end{tabular}




\begin{tabular}{|l|l|c|c|c|}
\hline \multirow{2}{*}{$\begin{array}{l}\text { Carlos III de } \\
\text { Madrid }\end{array}$} & $\begin{array}{l}\text { Información y conflicto I: los } \\
\text { medios ante la violencia }\end{array}$ & Obligatorio & 6 & $4^{\circ}$ \\
\cline { 2 - 5 } & $\begin{array}{l}\text { Información y conflicto II: el } \\
\text { papel de las religiones }\end{array}$ & Optativo & 6 & $4^{\text {o }}$ \\
\hline Miguel Hernández & Periodismo y criminalidad & Optativo & 6 & $4^{\text {o }}$ \\
\hline Valencia & Periodismo de conflictos y paz & Obligatorio & 4,5 & $4^{\text {o }}$ \\
\hline
\end{tabular}

Fuente: Elaboración propia

La mayoría de las asignaturas que se imparten en España posee una carga crediticia de 6 créditos ECTS ${ }^{2}$, si bien en el caso de la obligatoria de la U. de Valencia se reduce a 4,5 créditos. Frente a este dato negativo hay que valorar positivamente que salvo una excepción (U. Pompeu Fabra) las asignaturas optativas que se contemplan sí poseen esa carga crediticia.

En relación con la formación de los futuros periodistas, la Universidad Carlos III de Madrid es el centro con mayor número de asignaturas especializadas (2), créditos de carga lectiva (12) y amplitud de contenidos y temas. Constituye, por consiguiente, un interesante referente para orientar otros planes de estudio o, incluso, para el diseño y articulación de planes educativos de postgrado y especialización (másters, doctorados). Similar valía hay que otorgar a la propuesta de la Universidad de Valencia, por el carácter obligatorio de la asignatura y su amplio repertorio de materias en su programa docente.

\subsection{Materias objeto de estudio}

Entre los contenidos formativos que se contemplan en las diferentes asignaturas de las distintas titulaciones en Periodismo (o en Comunicación) que se analizaron asoman en el horizonte dos itinerarios genéricos (Tabla 2). El primero se vincula de un modo directo con el análisis, la comprensión y la cobertura de los acontecimientos que guardan relación con el conflicto como fenómeno sociopolítico, mediante un variado enfoque disciplinar (la situación de los derechos humanos, las relaciones internacionales, los conflictos étnicos y religiosos, los procesos de paz).

El segundo se concentra en abordar las manifestaciones de la violencia (crimen, conflictos armados, violencia de género, sucesos y tribunales). Así mismo, se aprecian diversas bifurcaciones que se dirigen a tres amplios apartados:

a) El conflicto como criterio de lo noticioso. El periodista ha de ser consciente de la variabilidad y riqueza conceptual que le ayude a diferenciar entre conflicto, agresividad y violencia (Rodrigo, 2003). También ha de dominar los principios del relato y las bases de la interpretación de la violencia. En el marco de los distintos géneros periodísticos (informativos, interpretativos, de opinión), resulta crucial la preparación técnica para el tratamiento de aquellos temas de interés general y relevancia pública cuyo eje central sean formas de conflicto y violencia de naturaleza estructural (terrorismo, enfrentamientos armados, conflictos raciales, violencia de género, 
violencia social...) en un marco temporal y social dados. Capacitar, en definitiva, para el análisis y descripción de situaciones de conflicto.

b) Los principios periodísticos ante las situaciones de conflicto y violencia. Los contenidos abarcan los siguientes temas y asuntos: 1 . Ética y deontología periodísticas: códigos, normativa, recomendaciones, libros de estilo, informes y estudios. 2. Investigación de la cobertura temática especializada: derechos humanos, periodismo de paz, terrorismo, guerra y conflictos armados, conflictos étnicos y raciales, violencia de género y doméstica, violencia en la calle (juvenil, escolar, deportiva...), conflictos sociales, laborales y medioambientales.

c) El ejercicio periodístico profesional. La propuesta educativa se orienta a la formación crítica para el análisis y práctica de la cobertura periodística de hechos y acontecimientos presididos por el conflicto y/o la violencia. De este modo, se persigue familiarizar al estudiante tanto con el ser real del ejercicio profesional como con el deber ser del quehacer periodístico.

Tabla 2. Grado en Periodismo. Materias objeto de formación sobre conflicto y violencia

\begin{tabular}{|c|c|c|c|c|c|c|c|c|c|}
\hline Universidad & 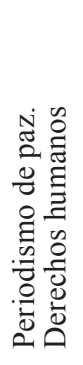 & 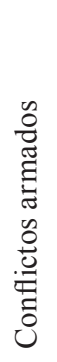 & 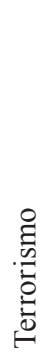 & $\begin{array}{l}\lambda \\
0 \\
0 \\
.0 \\
0 \\
0 \\
0 \\
0 \\
0 \\
0 \\
0 \\
0.0 \\
0.00 \\
0 \\
0.00 \\
0 \\
0\end{array}$ & 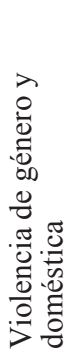 & 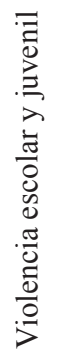 & $\begin{array}{l}\frac{0}{0} \\
0 \\
\frac{0}{0} \\
0 \\
\lambda \\
\frac{\pi}{0} \\
\frac{0}{0} \\
\frac{0}{0} \\
\frac{0}{7}\end{array}$ & 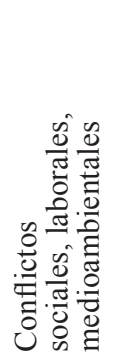 & 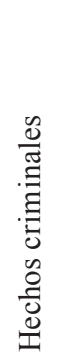 \\
\hline Valladolid & $\checkmark$ & & & & $\checkmark$ & $\checkmark$ & & & \\
\hline Pompeu Fabra & & & & & & & & & $\sqrt{3}$ \\
\hline $\begin{array}{l}\text { Carlos III de } \\
\text { Madrid }\end{array}$ & $\checkmark$ & $\checkmark$ & $\checkmark$ & $\checkmark$ & $\checkmark$ & $\checkmark$ & $\checkmark$ & & \\
\hline $\begin{array}{l}\text { Miguel } \\
\text { Hernández }\end{array}$ & & & & & & & & & $\sqrt{ }^{4}$ \\
\hline Valencia & $\checkmark$ & $\checkmark$ & $\checkmark$ & $\checkmark$ & $\checkmark$ & $\checkmark$ & $\checkmark$ & $\checkmark$ & \\
\hline
\end{tabular}

Fuente: Elaboración propia 


\section{Conclusiones}

En los estudios de Grado en Periodismo (o en Comunicación) que ofertan las universidades españolas resulta llamativamente pobre la presencia de asignaturas que se orienten de modo específico a la formación y capacitación del alumnado en las materias que se vinculan de manera específica con la información sobre todas aquellas áreas, hechos y acontecimientos que se relacionan con los conflictos y la violencia en la sociedad. Las asignaturas obligatorias están presentes solo en el 7,5\% de las titulaciones. La desatención educativa en este ámbito de la realidad social y profesional se agrava por el relevante carácter optativo de las materias que se ofertan $(50,0 \%)$.

La especialización de la temática concuerda con la tipología de los contenidos que se imparten y su ubicación en la estructura los planes de estudio (segundo ciclo, en especial durante el $4^{\circ}$ curso).

Se detectan dos tendencias. Una que vincula los contenidos con el análisis, comprensión y cobertura de los acontecimientos que guardan relación con el conflicto como fenómeno, mediante un variado enfoque (derechos humanos, relaciones internacionales, religiones, procesos de paz). Otra que se concentra en el abordaje de las diversas manifestaciones de la violencia (crimen, conflictos armados, sucesos, tribunales, derecho penal).

Se aprecia un llamativo olvido de los conflictos sociales, laborales o medioambientales que se integran en la cotidianeidad de la sociedad en cualquier lugar del mundo. Ignorar la existencia y consecuencias de las tensiones intergeneracionales, las disensiones entre la patronal y los obreros o las repercusiones del cambio climático resulta, cuando menos, una omisión clamorosa. Son temáticas de interés público, de permanente actualidad y las cubren a diario los medios de todo el planeta.

Se aprecian dos notables lagunas en el diseño y desarrollo explícito de los contenidos que se contemplan. La primera guarda relación con el conocimiento de la percepción y demanda social de esta clase de temáticas. La segunda, con el ejercicio profesional, esto es, con los aspectos prácticos de la elaboración del mensaje, pero también con las consecuencias que derivan de sus usos y abusos. Ahora bien, cabe la posibilidad de que estas particularidades de la labor periodística se programen en el bagaje ético y deontológico, sea de modo estructural o transversal, en el seno de la titulación

En relación con la formación de los futuros periodistas, la Universidad Carlos III de Madrid es el centro de educación superior con el Grado en Periodismo dotado de mayor número de asignaturas especializadas (2), carga crediticia lectiva (12 créditos) y por la amplitud de contenidos y temas (en línea similar, también destaca la Universidad de Valencia). Constituye, por consiguiente, un interesante referente para orientar otros planes de estudio o incluso para el diseño y articulación de planes educativos de postgrado y especialización profesional (másters, doctorados). 


\section{Referencias bibliográficas}

AGENCIA NACIONAL DE EVALUACIÓN DE LA CALIDAD Y ACREDITACIÓN (2005). Libro blanco. Títulos de Grado en Comunicación. Madrid: ANECA. ARENDT, H. (2006). Sobre la violencia. Madrid: Alianza Editorial.

BARRIOS, O. (ed.) (2002). Realidad y representación de la violencia. Salamanca: Universidad de Salamanca.

CALLEJA, J. M. (2013). La violencia como noticia. Madrid: Los libros de la Catarata.

CONGRESO INTERNACIONAL COMUNICACIÓN Y REALIDAD (CICR) (2003). Violencias y medios de comunicación: recursos y discursos. Barcelona, 9-10 mayo. Trípodos Extra 2003. Barcelona: Universitat Ramon Llull.

EUROPEAN JOURNALISM TRAINING ASOCIATION (EJTA) (2013). Declaración de Tartu. Disponible en: http://ejta.eu/the-tartu-declaration [18-07-2013].

GOMIS, L. (2008). Teoría de los géneros periodísticos. Barcelona: UOC.

INTERNATIONAL FEDERATION OF JOURNALISTS (IFJ) (2002). Putting Children in the Right. Guidelines for Journalists and Media Professionals. Bruselas: IFJ.

PENALVA, C. (2002). "El tratamiento de la violencia en los medios de comunicación”. Alternativas. Cuadernos de Trabajo Social, no 10. p. 395-412.

RODRIGO, Miquel (2003). “La narrativización de la violencia”. Quaderns del CAC, $\mathrm{n}^{\mathrm{o}} 17$. p. $15-21$.

SONTAG, S. (2003). Ante el dolor de los demás. Madrid: Alfaguara.

UNESCO (2007). Plan modelo de estudios de periodismo. París: Organización de las Naciones Unidas para la Educación, la Ciencia y la Cultura.

UNICEF (2005). Principios éticos para informar acerca de la infancia. Disponible en http://www.unicef.org/spanish/media/media_tools_guidelines.html [17-06-2011].

\section{Notas}

1. La Universidad de Vic ofrece en el Grado en Periodismo una asignatura optativa (6 créditos ECTS), que se imparte en inglés, denominada Conflictos y relaciones internacionales, pero su contenido no aborda aspectos relacionados con el ejercicio de la profesión periodística.

2. Las siglas aluden al European Credit Transfer System. Los créditos ECTS, en el EEES, representan el volumen de trabajo del estudiante para conseguir los objetivos del programa de estudios, objetivos que deben ser especificados preferiblemente en términos de resultados del aprendizaje y de competencias que han de ser adquiridas.

3. Aunque la asignatura se oferta para el curso 2013-2014, la guía docente no está disponible. Tampoco las aprobadas para cursos anteriores, por lo que se desconoce el detalle de los contenidos. 
4 La asignatura se oferta para el curso 2013-2014, pero en la guía docente no se detallan los contenidos específicos de la misma, aunque sí figuren las competencias generales y específicas, poco orientativas.

\section{La autora}

María de los Ángeles Galván Arias es licenciada en Ciencias de la Información (Periodismo) por la Universidad Complutense de Madrid. Ha sido becaria de doctorado e investigación en la Universidad CEU San Pablo. Su línea de investigación se centra en el tratamiento informativo y gráfico de la infancia en los medios de comunicación, en especial, en aquellos contextos en los que prima el conflicto y la violencia (guerra, terrorismo, conflictos étnicos, violencia de género, sucesos criminales, acoso escolar y violencia en el deporte). 